\title{
Negative concord in Washo as negative agreement
}

\author{
Emily A. Hanink*
}

\begin{abstract}
Washo, a Native American isolate, displays negative concord morphology in the context of negation. Negative concord in Washo comes in the form of the morpheme - $y a$, which may be suffixed onto optionally many sentential elements in a single clause. Given the apparent lack of semantic contribution by this morpheme, I argue - building on accounts along the lines of Zeijlstra (2004) - that negative concord in Washo is best treated as the result of multiple agreement between an interpretable Neg feature high in the clause and optionally many uninterpretable Neg features present on the items it c-commands. Importantly, the Washo data shed light on an unexplored system of negative concord and the possible range of agreement phenomena that are sensitive to negation.
\end{abstract}

Keywords. Negative concord; negation; agreement; Washo

1. Introduction. This paper concerns itself with an unfamiliar type of negative concord found in Washo, in which the suffix - ya occurs on optionally many sentential elements within the scope of negation. The examples in (1-2) illustrate this distribution by showing that - $y a$ may appear on the object t'ágim 'pinenuts' when the sentence is negated (1), and may not appear otherwise (2). ${ }^{1}$ Negation in Washo is expressed by the suffix -é:s.

mé:hu t’á:gim -ya P-í'iw -é:s -i
boy pinenuts-NC 3/3-eat-NEG-IND

'The boy didn't eat pinenuts.'

Washo Archive

$$
\begin{aligned}
& \text { *mé:hu t'á:gim -ya } \text { P-íPiw-i } \\
& \text { boy pinenuts-NC 3/3-eat-IND }
\end{aligned}
$$

'The boy ate pinenuts.'

While - $\eta a$ has been glossed informally as a "negative concord" morpheme in various works (i.a. Bochnak et al. 2011; Bochnak 2013; Hanink 2016, 2018), a dedicated investigation of the factors contributing to its licensing has not before been carried out. The aim of this paper is therefore twofold: to show that the suffix - ya i) is in fact a negative concord morpheme, but does not behave like one in the familiar sense of the term, and ii) is best treated as the realization of negative agreement. The Washo data therefore provide novel support for syntactic

\footnotetext{
*I am indebted to Adele James and the late Ramona Dick for the insights they've shared with me about their language. I am also grateful to Karlos Arregi, Ryan Bochnak, Jason Merchant, Asia Pietraszko, and Alan Yu for helpful discussion of this project, as well as the audience at the LSA 93 in NYC. Finally, I thank The Phillips Funds for Native American Research and the Mellon Foundation - University of Chicago Dissertation Completion Fellowship for funding this work. Author: Emily A. Hanink, University of Manchester (emily.hanink@ manchester.ac.uk)

${ }^{1}$ GLOSSES: DEP: dependent mood; DS: different subject; IND: independent mood; INTR: intransitivizing prefix; NC: negative concord; NEAR.FUT: near future; NEG: negation; NMLZ: nominalizer; R: reduplication; OBL: oblique; PL: plural; REFL: reflexive; REST: restrictive; SUBJ: subjunctive. Symbols deviating from the IPA are: L: [1]; M: [m]; š: $\left[\int\right] ; y:[j] ; Y:[j]$. Unless otherwise indicated, the data here come from the author's own fieldwork.
} 
accounts of negative concord in which dependent negative morphology is treated as a reflex of agreement (i.a. Zeiljstra 2004; Penka 2007; cf. Haegeman \& Londahl 2010).

The outline of this paper is as follows. In $\S 2$, I provide background on Washo and describe the wide distribution of $-\eta \eta a$ in the language. In $\S 3$, I discuss previous approaches to the analysis of negative concord, which I then show to be problematic for the Washo facts. In $\S 4$, I present a preliminary, agreement-based analysis based on current understanding of the data, and briefly discuss a potential confound in $\S 5$. $\S 6$ concludes.

2. Negative concord in Washo. Washo is a highly endangered Native American language spoken around Lake Tahoe in the United States. While largely considered to be an isolate, it has also been linked to the proposed Hokan group (Campbell, 1997; Mithun, 1999). The neutral word order of the language is SOV, with phrases being largely head-final (aside from nominal phrases and their modifiers, which are neutrally word-initial). The uncited data in this paper come largely from my fieldwork with speakers from the Washo community in Nevada.

The distribution of - $\eta \mathrm{a}$ in Washo is highly flexible. For example, it can occur on any argument of the verb, including subjects (3), direct objects (4) (repeated from (1)), and indirect objects (5), as long as that argument is under the scope of negation:

(3) subject:

béverli-na 2-í:bi-é:s-i

Beverly-NC 3-come-NEG-IND

'Beverly didn't come.'

Washo Archive

(4) direct object:

mé:hu t’á:gim-ya P-íPiw-é:s-i

boy pinenuts-NC 3/3-eat-NEG-IND

'The boy didn't eat pinenuts.'

(5) indirect object:

adél-ya PitbamušéPeš l-é:šìl-aša?-é:s-i

Adele-NC book 1/3-give-NEAR.FUT-NEG-IND

'I'm not going to give Adele a book.'

This suffix can also occur on non-arguments within the clause, for example on adverbs, as in (6), as well as on postpositional phrases, as in (7):

(6) adverb:

mí?le-w bajáya-ya ?-é:-gapil-é:s-i

all-PL outside-NC 3-go-around-NEG-IND

'No one is walking around outside.'

(7) postpositional phrase:

hútiwe?-ya dawyác'im-ıa ?álu?-ıa gum-M-í:k'i?-Pạaw-é:s-i

something-NC smoke-NC because.of-NC REFL-INTR-look-well-NEG-IND

'One can't see anything well because of the smoke.' 
Crucially, the appearance of this suffix is not limited to a single argument or constituent within the clause, as shown in examples (8-10):

$$
\begin{aligned}
& \text { damo?mó?mo?-ya t'elíliwhu-na P-í:gi-yé:s-i } \\
& \text { woman.R-NC man.R-NC 3/3-see-NEG-IND }
\end{aligned}
$$

'The women didn't see the men.'

(9) adél-ya ?wá?-ya P-ánal-é:s-i

Adele-NC here-NC 3-reside-NEG-IND

'Adele doesn't live here.'

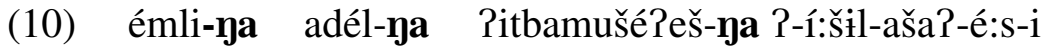

Emily-NC Adele-NC book-NC 3/3-give-NEAR.FUT-NEG-IND

'Emily is not going to give Adele a book.'

Finally, the negative concord suffix appears to be optional, in that negated sentences without any instances of - $-j a$ are perfectly acceptable (11a), and minimal pairs such as (11a-b) are judged by speakers to convey the same meaning:
a. da?mó?mo? pú:lul-a 1-1́:gi-yé:s-i
woman car-OBL 1/3-see-NEG-IND
'I don't see the woman in the car.'
b. da?mó?mo?-ya pú:lul-a-ıa 1-í:gi-yé:s-i
woman-NC car-OBL-NC 1/3-see-NEG-IND

'I don't see the woman in the car.'

\section{Negative concord and agreement.}

3.1 NeGATIVE CONCORD. Canonically, negative concord describes the co-occurence of a negative dependent with an independent expression of negation (see Giannakidou \& Zeijlstra 2017 for a recent overview). Crucially, the joint appearance of more than one instance of morphological negation in negative concord languages does not give rise to multiple negation in meaning. This phenomenon is exhibited in many European languages, for example in Italian (12) and Polish (13), in which sentential negation co-occurs with n-marked negative elements:

\section{(12) Italian}

Gianni *(non) ha visto niente

Gianni not has seen n-thing

'Gianni hasn't seen anything.'

Not: 'Gianni has not seen nothing.'

\section{(13) Polish}

Janek *(nie) pomaga nikomu

Janek not help n-person

'Janek doesn't help anybody.'

Not: 'Janek doesn't help nobody.'

Giannakidou \& Zeijlstra (2017: 8) 
In (12) and (13), the presence of the negative dependents niente and nikomu, respectively, does not result in a double negative reading. This differs crucially from the behavior of a language like Dutch, where each negative element contributes its own negation:

Jan belt niet niemand

Jan calls neg n-body

'Jan doesn't call nobody = Jan calls somebody'

Zeijlstra (2008: 2)

Negative dependents such as niente and nikomu in Italian (12) and Polish (13) are canonically referred to as $n$-words (Laka 1990; Giannakidou 2000), referring to the morphological shape in which they appear. Giannakidou (2006) offers the follow definition for such dependents:

n-words

An expression $\alpha$ is an $n$-word iff:

a. $\quad \alpha$ can be used in structures containing sentential negation or another $\alpha$-expression yielding a reading equivalent to one logical negation;

b. $\quad \alpha$ can provide a negative fragment answer.

Giannakidou (2006: 2) $)^{2}$

Based on this definition, - $y a$ is $n$-word-like with respect to condition (a): the dependent morphology is negative, yet only a single logical negation results. In fact, given the type of data we find in Washo, it is difficult to imagine what it would mean were -ya contributing an additional negative meaning in examples such as (16) (repeated from (9)):

Adél-na wá?-na ?-ánal-é:s-i

Adele-NC here-NC 3-reside-NEG-IND

'Adele doesn't live here.'

I note here that condition (b) does not apply to Washo, which seems to lack fragment answers entirely - even the polar answers 'yes' and 'no' - and so I do not discuss this condition.

3.2 SEMANTIC ACCOUNTS. Broadly speaking, there are two types of non-negative approaches to negative concord that treat it as a largely semantic phenomenon (see Giannakidou \& Zeijlstra 2017). The first treats $n$-words as indefinites (i.a. Ladusaw 1992, 1994; Acquaviva 1993, 1997; Giannakidou 1997; Richter \& Sailer 1998); the second treats them as universal quantifiers (i.a. Szabolcsi 1981; Giannakidou 1997, 2000; Sells 2006).

Neither of these treatments extend to Washo, for several reasons. First, n-words in Washo are instead n-morphemes. As such, the negative dependents observed in the language are not lexical items in their own right; rather, they are functional morphemes that occur on independent lexical items whose forms are otherwise invariant. Second, the distribution of - $n a$ is much more flexible in Washo than is generally found for $n$-words in more familiar negative concord languages, most crucially in that they are not limited to existential or universal meanings. The latter point can be seen, for example, from the fact that - $y a$ does not have an effect on scope relations. The examples in (17)-(18) show that the - $y a$ does not affect scope when it surfaces

\footnotetext{
${ }^{2}$ Cases in which only negation may license an $\alpha$-expression instantiate strict negative concord languages. Cases in which one $\alpha$-expression can license another are found in the so-called non-strict negative concord languages. Which class Washo falls into is pending further fieldwork, particularly in the domain of modified nominals.
} 
on an indefinite, either in subject or object position:

(17) Indefinite subject:

a. t'ánu $\varnothing$-p'ím-ewe?-é:s-i

person 3-go.out-hence-NEG-IND

'Someone didn't go out'

b. t'ánu-ya $\varnothing$-p'ím-ewe?-é:s-i

person-NC 3-go.out-hence-NEG-IND

'Someone didn't go out'

(18) Indefinite object:

a. Michelle hút'iwe? $\varnothing$-galá:m-é:s-i

Michelle thing 3/3-like-NEG-IND

'There's something Michelle doesn't like.'

b. Michelle hút'iwe?-na $\varnothing$-galá:m-é:s-i

Michelle thing-NC 3/3-like-NEG-IND

'There's something Michelle doesn't like.' $\quad \exists>\neg$

Similarly, parallel facts are observed in the domain of universal quantification (19-20):

Quantified subject:

a. míPle? P-îhuk'-é:s-i

all 3-dry-NEG-IND

'Not everything is dry.'

b. mí?le?-na 2 -íhuk' -é:s-i

all-NC 3-dry-NEG-IND

'Not everything is dry.'

(20) Quantified object:

a. míPle? l-é?w-aša?-é:s-i

all 1/3-eat-INT.FUT-NEG-IND

'I'm not going to eat everything.'

b. míPle?-na l-é?w-aša?-é:s-i

all-NC 1/3-eat-INT.FUT-NEG-IND

'I'm not going to eat everything.'

$\neg>\forall$

Nevertheless, the similarities that do exist between - $n a$ and $n$-words suggest that this morpheme should be thought of as a type of negative concord, albeit one that is unfamiliar from the view of better-studied languages.

3.3 NEGATIVE CONCORD AS AGREEMENT. In a different type of approach that is purely syntactic, Zeijlstra (2004) argues that negative concord is not a semantic phenomenon, but is instead the result of agreement (see also Penka 2007; Zeijlstra 2008). On this view, $n$-words are simply non-negative probes for Agree. According to Zeijlstra (2004), n-words are then a sub- 
set of strong NPIs that must be licensed by negation in the syntax, and that enter the derivation as semantically non-negative indefinites. Adopting a Minimalist approach of feature checking (along the lines of Chomsky (1995, 2000, 2001)), Zeijlstra proposes that these indefinites carry an uninterpretable $u$ NEG feature that must be checked against a higher, semantically negative element bearing an $i$ NEG feature, which for Zeijlstra is a non-pronounced negative operator high in the clause (in Spec, NegP), rather than any overt realization of negation.

A crucial part of his analysis is moreover the adoption of Multiple Agree (Hiraiwa 2001), which accounts for the availability of multiple $n$-words in a given agreement domain (cf. Haegeman \& Londahl 2010, who argue against the use of Multiple Agree in their account of West Flemish). In a nutshell, on this view, negative concord is reduced to multiple agreement between a negative operator and the negative items it c-commands (via Upward Agree; i.a. Merchant 2006, 2011; Baker 2008; Zeijlstra 2012).

3.4 Syntactic LiCENSING In WASHo. It was shown above that the suffix - ya in Washo displays behaviors consistent with better known instances of negative concord in European languages. For example, it also behaves like a strong NPI, in that it is licensed only by negation and not by, e.g., questions (21) or conditionals (22):

lák’a?(*-ya ) m-í:me?-ga?lám-he:š-i

one-NC 2-drink-want-Q-IND

'Do you want to drink one?'

$$
\begin{aligned}
& \text { mé:hu(*-ya ) wá?(*-ya ) } \text { P-é?-i šáwlamhu } \varnothing \text {-wagayána-hel-i-gi k'-é?-i } \\
& \text { boy-NC here-NC 3-be-IND girl } 3 \text { 3-talk.to-SUBJ-IND-NMLZ 3-be-IND } \\
& \text { 'If the boy were here, he would talk to the girl.' }
\end{aligned}
$$

Secondly, - $y a$ neither contributes any additional meaning of its own, nor does it have an effect on scope relations, ruling out an interpretation-based account. Taken together, these behaviors suggest that the most promising analysis on the market for Washo is one involving agreement.

Further evidence for an agreement analysis comes from the syntactic licensing conditions of - $y a$. First, - $y a$ is licensed only when in the scope of syntactic negation, which may come either in the form of sentential negation (23) (repeated from (2)), or constituent negation (24), both of which are realized by the suffix -é:s:

\section{Sentential negation}

mé:hu t’á:gim-na P-íPiw-é:s-i

boy pinenuts-NC 3/3-eat-NEG-IND

'The boy didn't eat pinenuts.'

\section{Constituent negation}

demuc'úc'u-ya t'-íPiw-é:s L-é?-i

candy-NC NMLZ-eat-NEG 1-be-IND

'I don't eat candy.' (='I am no candy eater.')

Washo Archive

Additionally, - $-g a$ is licensed only locally. This can be seen in the context of embedded clauses, which may not contain - $y a$-marked elements in the absence of clausemate negation. In 
(25) for example, the subject of the embedded clause, 'bird', may not bear negative concord morphology despite the presence of sentential negation on the matrix verb, 'dream':

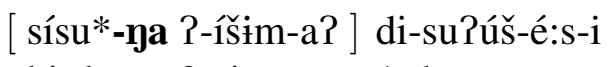

'I didn't dream that the bird sang.'

Relatedly, when certain prepositional phrases are added post-verbally, as something like an after-thought following a prosodic break, the negative concord suffix is not licensed:

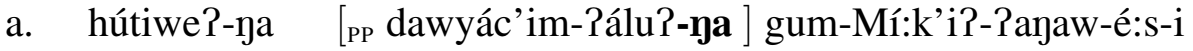
something-NC smoke-because.of-NC REFL-look/appear-good-NEG-IND
'One can't see anything because of the smoke.'
b. hútiwe?-ya gum-Mí:k'i?-Payaw-é:s-i [PP dawyác'im-?álu?(*-ya)] something-NC REFL-look/appear-good-NEG-IND smoke-because.of-NC

'One can't see anything...because of the smoke.'

Lastly, Washo has a small class of verbs that are semantically, but not syntactically negative. When these verbs are used, - $y a$ is licensed only when the negative marker -é:s is present. Note that in such cases, the resulting meaning of the verb is still positive:

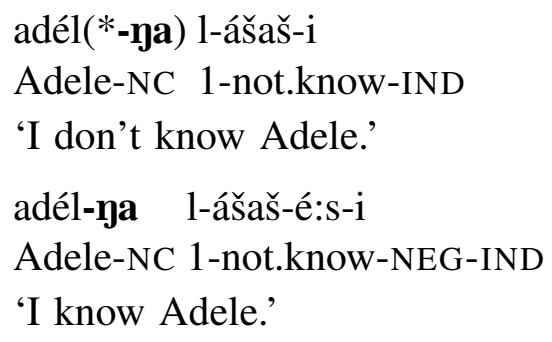

In sum, the licensing factors governing the distribution of -na are syntactic, rather than semantic, in nature; the data suggest that -na is i) clause-bound; ii) licensed by syntactic negation only, and iii) optional (cf. e.g., the West Flemish polarity-agreeing verbal prefix en- that may occur along with sentential negation (Haegeman 1998; Haegeman \& Londahl 2010)).

4. Towards an analysis. The appearance of the suffix - $y a$ in Washo appears to be an instance of negative concord licensed by syntactic negation. Building on proposals along the lines of Zeijlstra $(2004,2008)$, I therefore propose that - ga is best understood as the realization of multiple, negative agreement.

The core of the proposal has two ingredients. First, every element may come endowed with an unvalued, unintepretable neg feature $u$ Neg. Second, this feature can be checked by agreeing upward with the syntactic negation c-commanding it, which bears a matching interpretable feature $i \mathrm{Neg}$. As for Zeijlstra, the availability of Multiple Agree (Hiraiwa 2001) explains why the appearance of $-\eta y a$ is so free: optionally many instances of a $u$ Neg feature may be checked in the same clause by a single goal bearing a matching interpretable feature. These aspects of the analysis are schematized in (29b) for an example like (29a) (repeated from (9)): 
a. adél-ya wá?-ya P-ánal-é:s-i

Adele-NC here-NC 3-reside-NEG-IND

'Adele doesn't live here.'

b.

$$
\text { [CP Adél } \left.{ }_{[u \mathrm{NEG}]} \text { wáP }_{[u \mathrm{NEG}]}\left[\mathrm{C} \text { Pánalé:si } i_{[i \mathrm{NEG}]}\right]\right]
$$

Note that this implementation of the analysis differs crucially from Zeijlstra (2004), according to which the sentential elements bearing $u$ NEG are necessarily indefinite: In Washo, $u$ NEG is free to occur on anything.

Unlike Zeijlstra moreover, the negative element I assume to bear $i \mathrm{Neg}$ is (sentential) negation itself. This is sufficient in the general case, as Washo is an SOV language, and the negative suffix is high enough in the clausal periphery such that the c-command condition for Agree will be met. The structure of a clause such as (30a), for example, is schematized in (30b). The negative suffix is hosted by its own projection, NegP, which intervenes between TP and MoodP, the clausal anchor in Washo (see Bochnak (2016); Hanink \& Bochnak (2018) for more on MoodP in Washo). ${ }^{3}$ This ordering is consistent with the morphology of the language, in accordance with the Mirror Principle (Baker 1985).
a. 1-é:me?-aša?-é:s-i
1-drink-NEAR.FUT-NEG-IND
'I'm not going to drink.'

Jacobsen (1973)

b.

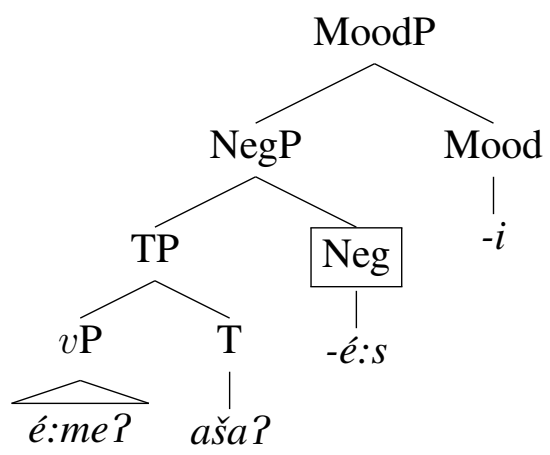

Note that there is no evidence for the subject moving higher than Spec, TP in Washo (cf. Arregi \& Hanink 2018), though one potential issue for this assumption comes from whmovement. Washo is an optional $w h$-movement language, and so we might expect $w h$-words that have undergone movement to be outside the scope of negation. The behavior of - $n a$ with respect to $\bar{A}$-movement requires further investigation. ${ }^{4}$

5. Ruling out other licensing factors. In the remainder of this paper, I offer a brief discussion regarding the issue of ruling out other factors that might contribute to the licensing of the negative concord suffix in Washo. The reason for this discussion is that the interaction of nega-

\footnotetext{
${ }^{3}$ As pointed out by Zeijlstra (2008), Jespersen's Generalization predicts that every language in which the negative marker is a head should exhibit negative concord. Washo is in line with this generalization.

${ }^{4}$ Relative clauses in Washo, however, are always internally-headed (Jacobsen 1998; Hanink 2016, 2018).
} 
tion with other (semantic/pragmatic) factors can be notoriously difficult to understand, e.g., the seemingly superfluous VP-final nie in Afrikaans, which Merchant (2017) treats as a negativeisotope VP-level clitic; the augment morpheme across Bantu, which may or not be sensitive to negation (i.a. Mzolo 1968; Halpert 2012); the genitive of negation in languages such as Russian (see i.a. Brown 2010; Partee \& Borschev 2002), where the optional genitive case marking of sentential elements under the scope of negation has been argued to be sensitive to semantic or pragmatic factors.

Based on such complications, one factor that remains to be understood in Washo is whether - ya contributes some semantic meaning that is not immediately obvious in a fieldwork setting. A good contender for such a contribution might come, for example, from focus, a domain with which negative concord has been closely tied before (e.g., Watanabe (2004) on Japanese). Preliminary work suggests that focus does not play a role, however. First, the negative concord suffix is not obligatory in clear focus contexts involving negation, such as in (31): ${ }^{5}$
a. Lisa dewYúli ?-í:gi-yé:s-i t’áš-k’en ?-í:gi-yi
Lisa ghost-NC 3-see-NEG-IND shirt-REST 3-see-IND
'Lisa didn't see a ghost, she just saw a shirt.'
b. Lisa dewYúli-na ?-í:gi-yé:s-i t’áš-k'en ?-í:gi-yi
Lisa ghost-NC 3-see-NEG-IND shirt-REST 3-see-IND
'Lisa didn't see a ghost, she just saw a shirt.'

Second, there are specific contexts in elicitation that do not lend themselves to a focus interpretation. One such context is given in (32), where the context involves a first mention of a particular 'big rock', backgrounding it. For this reason, focus-marking should not be expected on 'big rock' in the follow-up utterance. Nevertheless, - ja appears:

(32) Context: you go walking, and someone asks if you saw the big rock by the lake.

déPek t'íyeli?-na 1-í:gi-yé:s-i

rock big-NC 1-see-NEG-IND

'I didn't see the big rock.'

Third, - $y a$ is never licensed without negation in non-negative focus contexts, as in (33), which contains the focus-sensitive restrictive suffix $-k$ ' $e \eta$, which means something like 'only':

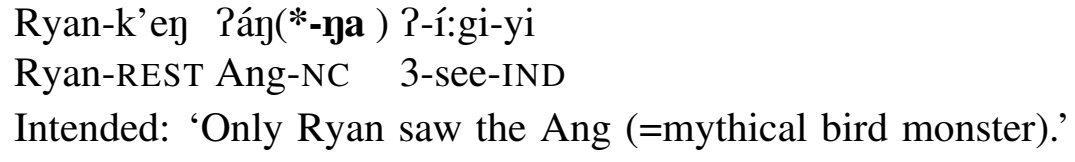

The upshot of this is that focus does not seem to be at play, though that does not necessarily rule out the contribution of other semantic or pragmatic factors to the licensing of - $y a$. More fieldwork is needed to determine whether such other factors exist. Importantly however, the syntactic licensing conditions for negative concord remain. If there are in fact other factors governing the appearance of $-\eta \exists a$, the only aspect of the analysis presented in $\S 4$ that would change would be the optionality of this morpheme.

\footnotetext{
${ }^{5}$ I thank Ryan Bochnak for helping me to collect these data during my absence from the field.
} 
6. Conclusion. The negative concord suffix -na in Washo presents a novel type of negative agreement marking that is best captured by an agreement analysis invoking Multiple Agree, along the lines of the proposal put forward by Zeijlstra (2004). The Washo data presented in this paper are important in two ways. First, they expand our understanding of the possible range of agreement phenomena, as they present a hitherto unfamiliar system of negative agreement. Second, they show with direct evidence that agreement analyses of negative concord are on the right track, at least for certain languages.

\section{References}

Acquaviva, Paolo. 1993. The logical form of negation: A study of operator-variable structures in syntax: Scuola Normale Superiore, Pisa dissertation.

Acquaviva, Paolo. 1997. The logical form of negation: A Study of operator-variable structures in syntax. New York: Garland.

Arregi, Karlos \& Emily A. Hanink. 2018. Switch reference in Washo as multiple subject agreement. In Sherry Hucklebridge \& Max Nelson (eds.), Proceedings of the North East Linguistic Society 48, vol. 1. 39-48. GLSA Publications.

Baker, Mark. 1985. The mirror principle and morphosyntactic explanation. Linguistic Inquiry 16.3. 373-415.

Baker, Mark C. 2008. The Syntax of agreement and concord. Cambridge University Press.

Bochnak, M. Ryan. 2013. Cross-linguistic variation in the semantics of comparatives: University of Chicago dissertation.

Bochnak, M. Ryan. 2016. Past time reference in a language with optional tense. Linguistics and Philosophy 39. 247-294.

Bochnak, M. Ryan, Timothy Grinsell \& Alan Yu. 2011. Copula agreement and the stagelevel/individual-level distinction in Washo. In Meagan Louie \& Alexis Black (eds.), UBC Working Papers in Linguistics: Proceedings of the 16th Workshop on the Structure and Constituency in the Languages of the Americas, The University of British Columbia.

Brown, Sue. 2010. The syntax of negation in Russian: A Minimalist approach. CSLI Publications.

Campbell, Lyle. 1997. American Indian languages: The historical linguistics of Native America. Oxford University Press.

Chomsky, Noam. 1995. The Minimalist Program. The MIT Press.

Chomsky, Noam. 2000. Minimalist Inquiries: the framework. In R. Martin, D. Michaels \& J. Uriagereka (eds.), The view from Building 20: Essays in honor of Sylvain Bromberger. 89-155. MIT Press.

Chomsky, Noam. 2001. Derivation by phase. In Michael Kenstowicz (ed.), Ken Hale: A life in language, 1-52. MIT Press.

Giannakidou, Anastasia. 1997. The landscape of polarity items: University of Groningen dissertation.

Giannakidou, Anastasia. 2000. Negative ... concord? Natural Language \& Linguistic Theory 18. 457-523.

Haegeman, Liliane. 1998. Verb movement in embedded clauses in West Flemish. Linguistic 
Inquiry 29. 631-656.

Haegeman, Liliane \& Terje Londahl. 2010. Negative concord and (multiple) Agree: A Case

Study of West Flemish. Linguistic Inquiry 41. 181-211.

Halpert, Claire. 2012. Argument licensing and agreement in Zulu. Cambridge, MA: Massachusetts Institute of Technology dissertation.

Hanink, Emily. 2016. Internally headed relatives and event nominalizations in Washo. In The Proceedings of BLS 42. 119-134. UC Berkeley.

Hanink, Emily. 2018. Structural sources of anaphora and sameness: University of Chicago dissertation.

Hanink, Emily \& M. Ryan Bochnak. 2018. Factivity and two types of embedded clauses in Washo. In A. Lamont \& K. Tetzlof (eds.), Proceedings of the North East Linguistic Society 47. 65-78. GLSA Publications.

Hiraiwa, Ken. 2001. Multiple agree and the defective intervention constraint in Japanese. In MIT Working papers in Linguistics 40. 57-80.

Jacobsen, William. 1973. A rhythmic principle in Washo morphotactics. Paper presented at the Symposium on California Indian Linguistics, Southwestern Anthropological Association, San Francisco, CA.

Jacobsen, William. 1998. Headless relative clauses in Washo. In Leanne Hilton \& Pamela Munro (eds.), Studies in American Indian languages: Description and theory, 102-116. Berkeley, CA: University of California Press.

Ladusaw, William A. 1992. Expressing Negation. In Chris Barker \& David Dowty (eds.), Proceedings of Semantics and Linguistic Theory 2. 237-259. Cornell University.

Ladusaw, William A. 1994. Thetic and categorical, stage and individual, weak and strong. In Mandy Harvey \& Lynn Santelmann (eds.), Proceedings of Semantics and Linguistic Theory (SALT) 4, 220-229. Cornell University.

Laka, Itziar Murgaza. 1990. Negation in syntax: On the nature of functional categories and projections: Massachusetts Institute of Technology dissertation.

Merchant, Jason. 2006. Polyvalent case, geometric hierarchies, and split ergativity. In Jackie Bunting, Sapna Desai, Robert Peachey, Chris Straughn \& Zuzana Tomkova (eds.), Proceedings from the Annual Meeting of the Chicago Linguistic Society, vol. 2: The Parasessions. 47-67. Chicago Linguistic Society.

Merchant, Jason. 2011. Aleut case matters. In Pragmatics and Autolexical Grammar: In honor of Jerry Sadoc. 382-411. John Benjamins: Amsterdam.

Merchant, Jason. 2017. The Afrikaans final negative particle as a negative isotopic, VP-level clitic. Manuscript, University of Chicago.

Mithun, Marianne. 1999. The languages of North America. Cambridge University Press.

Mzolo, D. 1968. The Zulu noun without the initial vowel. African Studies 27. 195-210.

Partee, Barbara \& Vladimir Borschev. 2002. Genitive of negation and scope of negation in Russian existential sentences. Annual Workshop on Formal Approaches to Slavic Linguistics: the Second Ann Arbor Meeting. Scholarworks at UMass.

Penka, Doris. 2007. Negative indefinites: Universit”at T"ubingen dissertation. 
Richter, Frank \& Manfred Sailer. 1998. LF constraints on expressions of Ty2: An HPSG analysis of negative concord in Polish. In Robert D. Borsley \& Adam Przepi'orkowski (eds.), Slavic in Head-Driven Phrase Structure Grammar. 247-282. CSLI Publications.

Sells, Peter. 2006. Interactions of negative polarity items in korean. In The Proceedings of the 11th Harvard International Symposium on Korean Linguistics. 724-737.

Szabolcsi, Anna. 1981. The semantics of topic/focus articulation. In Jeroen Groenendijk, Theo Janssen \& Martin Stokhof (eds.), The handbook of phonological theory, 513-540. Mathematical Center.

Watanabe, Akira. 2004. The genesis of negative concord: Syntax and morphology of negative doubling. Linguistic Inquiry 35(4). 559-612.

Zeijlstra, Hedde. 2008. On the syntactic flexibility of formal features. In Theresa Biberauer (ed.), The limits of syntactic variation, 143-173. Amsterdam: John Benjamins.

Zeijlstra, Hedde. 2012. There is only one way to agree. The Linguistic Review 29. 491-539. 